\title{
CT MEASUREMENT OF GLENOID EROSION IN ARTHRITIS
}

\author{
A. B. MULLAJI, F. H. BEDDOW, G. H. R. LAMB \\ From the Royal Liverpool University Hospital, England
}

We studied serial CT scans of 45 arthritic shoulders (34 rheumatoid, 11 osteoarthritic) and 19 normal shoulders, making measurements at three levels on axial images.

The maximum anteroposterior diameter of the glenoid was increased in rheumatoid glenoids at the upper and middle levels by $6 \mathrm{~mm}$ and in osteoarthritic glenoids at all levels by 5 to $8 \mathrm{~mm}$ as compared with normal. In rheumatoid cases, nearly half the available surface of the glenoid was of unsupported bone, mainly posteriorly at the upper and middle levels. In osteoarthritic glenoids, the best supported bone was anterior at the upper level and central at the middle and lower levels. The depth of the rheumatoid glenoid was reduced by a mean of $6 \mathrm{~mm}$ at the upper and middle levels and by $3 \mathrm{~mm}$ at the lower level. This inclined the surface of the glenoid superiorly. The depth at the middle level in osteoarthritis was reduced by a mean of $5 \mathrm{~mm}$, suggesting central protrusion. Osteoarthritic glenoids were retroverted by a mean of $12.5^{\circ}$, but of rheumatoid glenoids two-thirds were retroverted (mean $15.1^{\circ}$ ) and one-third anteverted (mean $8.2^{\circ}$ ).

Our findings have important implications for the planning and placement of the glenoid component of total shoulder replacements; CT can provide useful information.

J Bone Joint Surg [Br] 1994; 76-B:384-8.

Received 31 March 1993; Accepted after revision 22 July 1993
Total shoulder replacement is one of the most technically demanding arthroplasties (Neer and Morrison 1988). Apart from problems with the reconstruction of the rotator cuff, the correct placement and orientation of implants are critical (Neer, Watson and Stanton 1982). Only a small volume of bone is available for fixation in the glenoid (Cofield 1984), especially when there has been extensive destruction by the disease process.

Neer and Morrison (1988) found that $14.7 \%$ of shoulders had enough destruction of the glenoid to make implantation of the prosthesis impossible without bone grafting. Glenoid bone stock was deficient in $20.7 \%$ of the shoulders treated by McCoy et al (1989) and in 62\% of those treated by Kelly, Foster and Fisher (1987). Preoperative assessment of the glenoid by radiographs alone often gives a false impression of its size (Lettin, Copeland and Scales 1982), and most radiological studies of arthritic shoulders have concentrated on the humeral head and neglected glenoid pathology (Sillar et al 1979; Crossan and Vallance 1980; Deutsch, Resnick and Mink 1985). Glenoid involvement in the rheumatoid shoulder varies considerably, and erosion has been reported to occur posteriorly (Neer 1985), centrally or superiorly (Cofield 1984), and anteriorly or centrally (McCoy et al 1989).

There has been little previous work on this subject although accurate placement and adequate osseous support for the glenoid component are important (Barrett et al 1987). We have tried to determine the extent and pattern of glenoid erosion in rheumatoid and osteoarthritis using CT.

\section{PATIENTS AND METHODS}

Our prospective study was between January 1987 and May 1992 at the Royal Liverpool University Hospital. All patients of the senior author (FHB) with rheumatoid or osteoarthritis who were candidates for a total shoulder replacement, had preoperative CT. There were 34 shoulders ( 18 right) in 24 patients ( 20 female) with seropositive rheumatoid arthritis (mean age 60 years; range 34 to 80 ), and 11 shoulders ( 8 right) in ten patients ( 8 female) with osteoarthritis (mean age 64.9 years; range 26 to 80 ).

An IGE 9800 CT scanner (GE Medical Systems, Milwaukee, Wisconsin) provided axial images, which were viewed at window settings appropriate for bone and soft-tissue detail. Standard horizontal slices were taken from the base of the coracoid downwards at $5 \mathrm{~mm}$ 
intervals, and the glenoid was studied at three levels: upper (base of the coracoid), middle, and lower at $10 \mathrm{~mm}$ intervals.

The measurements taken at each of the three levels are shown in Figure 1.

1) Maximum anteroposterior diameter (A).

2) Position and extent of unsupported bone anteriorly $\left(A_{1}\right)$ and posteriorly $\left(\mathrm{A}_{2}\right)$.

3) Position and extent of supported bone (B).

4) Medial displacement, as a measure of the depth of the

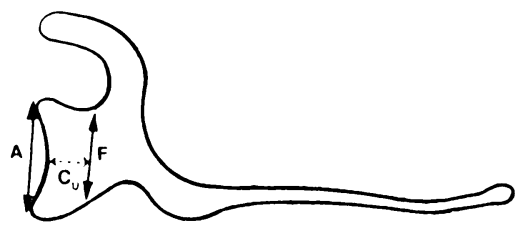

UPPER LEVEL

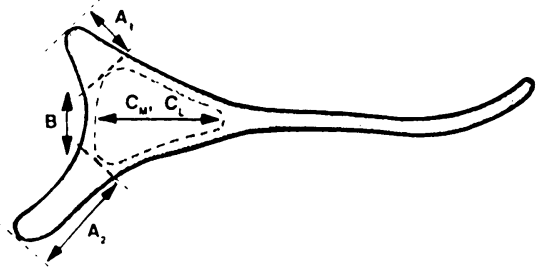

MIDDLE AND LOWER LEVELS
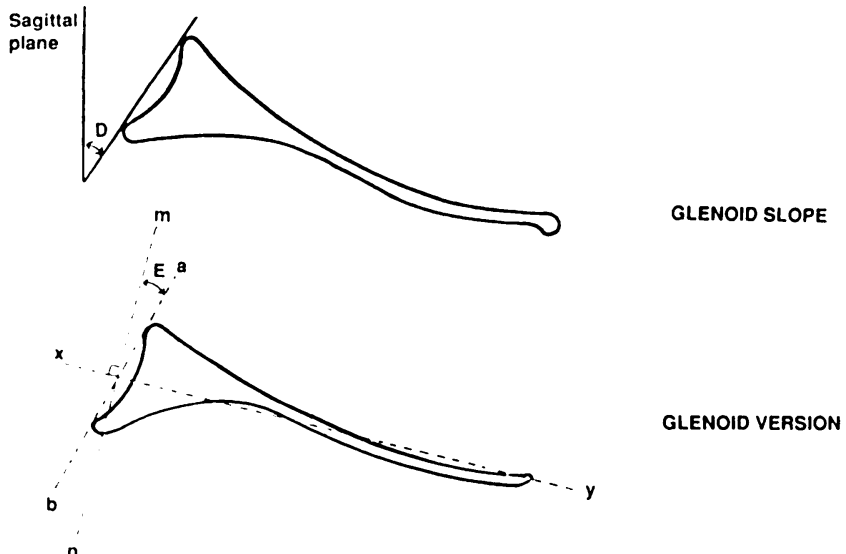

Fig. 1

Diagram to show the methods of making various measurements on axial images through the upper, middle and lower levels of the glenoid (see text). glenoid, was recorded as the reduction of the perpendicular distance from the base of the coracoid to the joint surface at the upper $\left(\mathrm{C}_{\mathrm{U}}\right)$, middle $\left(\mathrm{C}_{\mathrm{M}}\right)$ and lower $\left(\mathrm{C}_{\mathrm{L}}\right)$ levels.

5) Slope of the glenoid, as the angle $D$ between the sagittal plane and a line drawn between the anterior and posterior margins.

6) Version of the glenoid in relation to the plane of the scapula (xy), which is defined as a line from the midpoint (Randelli and Gambrioli 1986) of the glenoid (disregarding osteophytes) and the medial edge of the scapula. The angle $E$ is that between a line joining the anterior and posterior margins of the glenoid and a line perpendicular to the scapular plane. This is recorded as anteversion if the glenoid is open anteriorly, and retroversion if it faces posteriorly.

7) Width of the scapular neck (F) at the upper level.

Measurements were made using dividers, and angular measurements were expressed in degrees.

The CT scans of 19 normal shoulders (12 rightsided) in 16 patients (8 female) (Fig. 2) who had scans for other reasons were used to derive normal values. Their ages ranged from 24 to 80 years (mean 55).

We used the unpaired Student's $t$-test to determine statistical significance, with a significance level of $p<0.05$. Ten scans chosen at random were read independently by two of the authors (ABM and GHRL), each on two separate occasions without knowledge of previous readings to determine interobserver and intraobserver differences.

\section{RESULTS}

Table I summarises the results. In rheumatoid arthritis, the maximum anteroposterior diameter of the glenoid was greater than normal at the upper and middle levels by $6 \mathrm{~mm}$; in osteoarthritis it was 5 to $8 \mathrm{~mm}$ greater than normal $(p<0.05)$. Much of the apparent glenoid surface consisted only of osteophytes and unsupported bone, especially posteriorly at the upper and middle levels in cases of rheumatoid arthritis, where it formed nearly half the available surface (Fig. 3). At the lower level, supported medullary bone was found to lie centrally.

Osteoarthritic glenoids had more supported bone

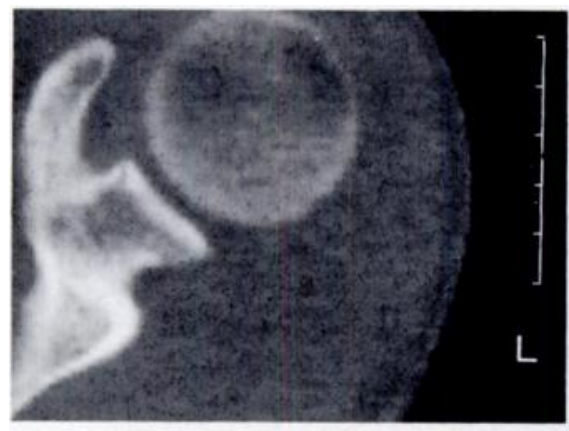

Fig. 2a

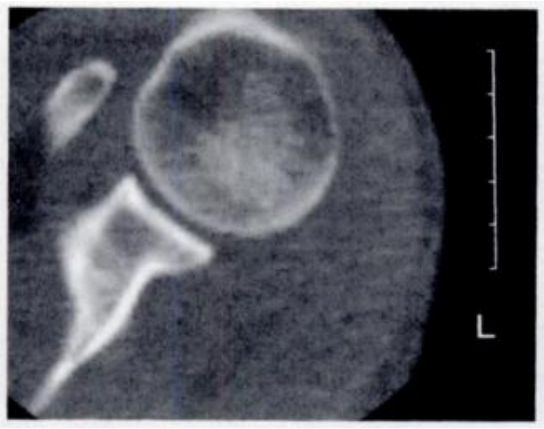

Fig. $2 b$

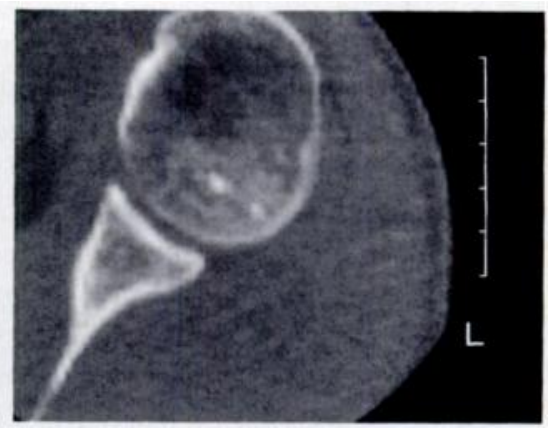

Fig. 2c

CT scans of a normal shoulder showing a typical glenoid at the upper (a), middle (b), and lower levels (c). 


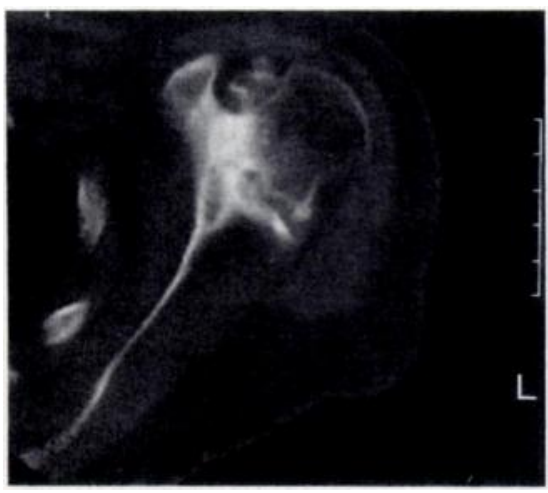

Fig. 3a

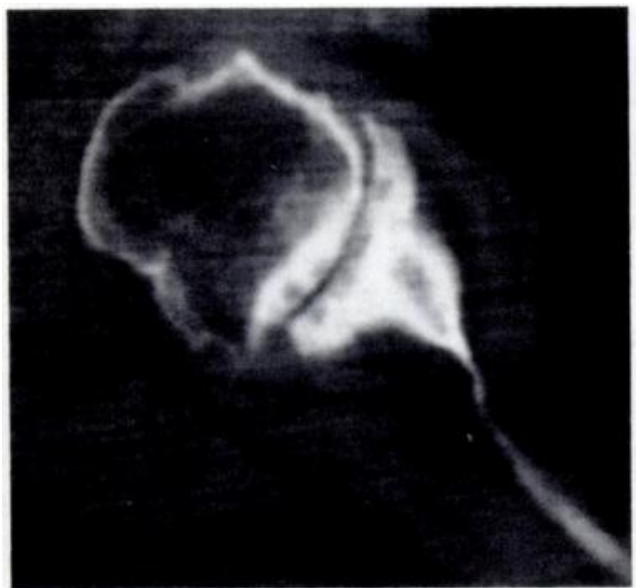

Fig. 4

CT scan of a typical osteoarthritic shoulder showing glenoid retroversion with an anterior osteophyte.

than rheumatoid ones at nearly all levels. Osteophytes were seen not only posteriorly but also anteriorly (Fig. 4). Supported bone was present anteriorly at the upper level but was more common centrally at the middle and lower levels.

As regards the medial displacement of the glenoid, the distance from the joint surface to the plane of the base of the coracoid was reduced by $6 \mathrm{~mm}$ at the upper level in rheumatoid arthritis $(\mathrm{p}<0.05)$ and by $6 \mathrm{~mm}$ and $3 \mathrm{~mm}$ at the middle and lower levels respectively $(p<0.05)$. In osteoarthritis, however, superior and inferior erosion was not significant, although the joint surface was medially displaced at the middle level by $5 \mathrm{~mm}(\mathrm{p}<0.05)$.

All but one of the osteoarthritic glenoids were retroverted (mean $12.5^{\circ}$ ) with a mean slope of $28.6^{\circ}$, significantly different from the mean normal retroversion of $3^{\circ}$ and slope of $39.9^{\circ}(p<0.05)$. In rheumatoid arthritis, about two-thirds of the glenoids were retroverted (mean $15.1^{\circ}$ ) with a slope of $35.6^{\circ}$ (see Fig. 3a) and the others were anteverted (mean $8.2^{\circ}$ ) with a slope of $41.4^{\circ}$ (see Fig. 3b). The width of the scapular neck was unaffected by either rheumatoid or osteoarthritis. Interobserver and intraobserver differences were less than $2 \mathrm{~mm}$ for linear measurements and less than $2^{\circ}$ for angular measurements.

\section{DISCUSSION}

The normal pear shape of the glenoid cavity was confirmed by the increasing maximum anteroposterior diameter from upper to lower levels. In normal shoulders, our results for the mean upper diameter $(23.3 \mathrm{~mm} \pm 3.9 \mathrm{sD})$ and lower diameter $(26.3 \mathrm{~mm} \pm 3.4)$ corresponded closely to those reported by Iannotti et al (1992) $(23 \mathrm{~mm} \pm 2.7$ and $29 \mathrm{~mm}$ \pm 3.1 ). Similarly, the mean retroversion of $3^{\circ}$ which we recorded for normal shoulders is close to the $2^{\circ}$ reported by Randelli and Gambrioli (1986) from CT scans and the $7^{\circ}$ from radiographs by Cyprien et al (1983). Friedman, Hawthorne and Genez (1992), however, using CT found a mean of $2^{\circ}$ of anteversion in normal shoulders $\left(14^{\circ}\right.$ anteversion to $12^{\circ}$ retroversion). Like Deutsch et al (1985) we found that the normal glenoid surface was progressively more anteverted in the lower slices.

We have not found any previous descriptions of glenoid erosion in arthritic shoulders. In rheumatoid arthritis we found two patterns of erosion. The more frequent type had predominantly posterior wear, causing

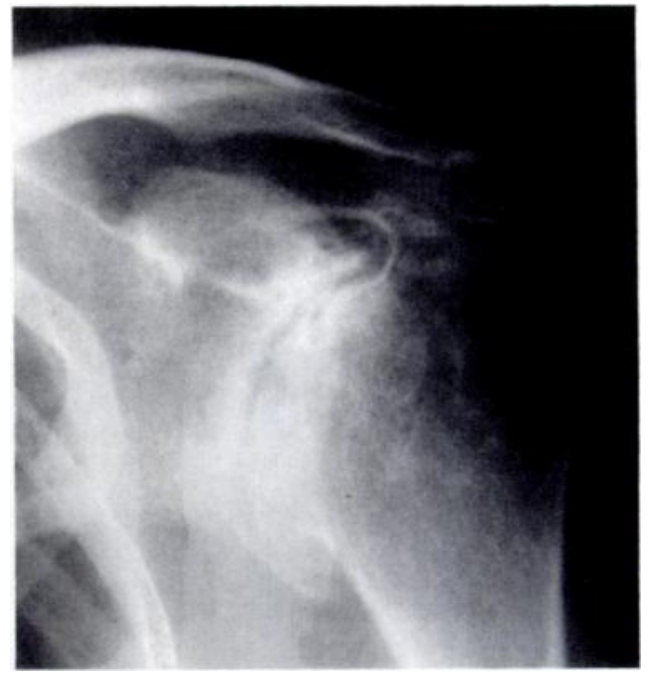

Fig. 5

Radiograph of the shoulder of a rheumatoid patient (scan in Figure 3a). The radiograph fails to show the true extent of glenoid erosion and the extremely deficient bone stock. 
Table I. Results of measurement of CT scans of the glenoid in the three groups (mean \pm $1 \mathrm{SD})$, with the percentage of shoulders in each category in parentheses

\begin{tabular}{|c|c|c|c|}
\hline & $\begin{array}{l}\text { Normal } \\
(n=19)\end{array}$ & $\begin{array}{l}\text { Rheumatoid } \\
(n=34)\end{array}$ & $\begin{array}{l}\text { Osteoarthritic } \\
(n=11)\end{array}$ \\
\hline \multicolumn{4}{|c|}{ Maximum diameter (A) (mm) } \\
\hline Upper & $23.3 \pm 3.9$ & $29.7 \pm 6.4$ & $30.6 \pm 7.4$ \\
\hline Middle & $25.5 \pm 3.5$ & $31.1 \pm 5.7$ & $33.3 \pm 5.7$ \\
\hline Lower & $26.3 \pm 3.4$ & $28.7 \pm 5.7$ & $31.6 \pm 6.9$ \\
\hline \multicolumn{4}{|l|}{ Unsupported bone (mm) } \\
\hline \multicolumn{4}{|l|}{ Anterior $\left(A_{1}\right)$} \\
\hline Upper & $\mathbf{0}$ & 0 & $10.1 \pm 3.1$ \\
\hline Middle & $\mathbf{0}$ & $10.9 \pm 4.2$ & $10.8 \pm 2.2$ \\
\hline Lower & $\mathbf{0}$ & $9.7 \pm 3.5$ & $11.6 \pm 4.4$ \\
\hline \multicolumn{4}{|l|}{ Posterior $\left(\mathbf{A}_{2}\right)$} \\
\hline Upper & $\mathbf{0}$ & $16.9 \pm 4.5$ & $14.0 \pm 4.9$ \\
\hline Middle & 0 & $14.9 \pm 4.7$ & $12.1 \pm 5.4$ \\
\hline Lower & 0 & $9.9 \pm 4.6$ & $9.5 \pm 3.1$ \\
\hline \multirow{2}{*}{\multicolumn{4}{|c|}{ Supported bone (B) (mm) }} \\
\hline \multicolumn{2}{|l|}{ Upper } & & \\
\hline Anterior & & $13.9(85.3)$ & $17.9(63.6)$ \\
\hline Anterior + Posterior & $23.3(100)$ & $22.6(14.7)$ & $23.3(27.3)$ \\
\hline Posterior & & & $12.0(9.1)$ \\
\hline \multicolumn{4}{|l|}{ Middle } \\
\hline Anterior & & $15.1(76.5)$ & $21.0(36.6)$ \\
\hline Anterior + Posterior & $25.5(100)$ & $27.9(20.8)$ & $25.0(18.2)$ \\
\hline Posterior & & $11.0(2.3)$ & $25.0(18.2)$ \\
\hline Central & & & $11.0(27.3)$ \\
\hline \multicolumn{4}{|l|}{ Lower } \\
\hline Anterior & & $18.1(20.5)$ & \\
\hline Anterior + Posterior & $26.3(100)$ & $25.3(44.2)$ & $25.0(36.4)$ \\
\hline Posterior & & $19.8(14.7)$ & $18.5(36.4)$ \\
\hline Central & & $15.7(20.5)$ & $15.0(27.3)$ \\
\hline \multicolumn{4}{|l|}{ Depth* (C) (mm) } \\
\hline Upper & $9.6 \pm 1.8$ & $2.9 \pm 3.1$ & $9.2 \pm 3.6$ \\
\hline Middle & $28.5 \pm 4.9$ & $22.5 \pm 5.8$ & $23.4 \pm 7.4$ \\
\hline Lower & $25.8 \pm 3.4$ & $22.8 \pm 6.2$ & $24.1 \pm 6.1$ \\
\hline \multicolumn{4}{|l|}{ Slope (D) (degrees) } \\
\hline Upper & $35.8 \pm 10.7$ & $35.0 \pm 11.2$ & $24.4 \pm 10.7$ \\
\hline Middle & $40.6 \pm 7.5$ & $38.2 \pm 9.9$ & $30.5 \pm 10.3$ \\
\hline Lower & $43.2 \pm 7.6$ & $39.5 \pm 10.2$ & $30.9 \pm 12.5$ \\
\hline Mean & $39.9 \pm 8.2$ & $37.5 \pm 9.2$ & $28.6 \pm 10.8$ \\
\hline \multicolumn{4}{|l|}{ Version (E) (degrees) } \\
\hline Anteversion & $2.2 \pm 2.8(22.2)$ & $8.2 \pm 4.4(32.3)$ & $3.0 \quad(9.1)$ \\
\hline Retroversion & $5.1 \pm 4.8(61.1)$ & $15.1 \pm 8.1(67.6)$ & $14.1 \pm 8.9(90.9)$ \\
\hline 0 degrees & $0 \quad(16.6)$ & & \\
\hline Mean & 3 deg retroversion & 7.6 deg retroversion & 12.5 deg retroversion \\
\hline Neck width (F) (mm) & $20.9 \pm 2.3$ & $20.4 \pm 4.3$ & $21.8 \pm 3.9$ \\
\hline
\end{tabular}

* see text

glenoid retroversion. About one-third of rheumatoid glenoids had severe anterior destruction and an anteverted surface. In both types, medial displacement of the glenoid surface was greatest at the upper and middle levels: the surface was inclined superiorly rather than inferiorly. The best bone was in the anterior half at the upper and middle levels, with the remaining surface at these levels consisting of unsupported bone. The lower level was least affected.

In osteoarthritic shoulders, the glenoid was almost always retroverted and its depth was most affected at the middle level, suggesting central protrusion. There was more supported bone than in rheumatoid glenoids at all levels, with the best bone anteriorly at the upper level and centrally at the middle and lower levels.

Our findings have implications for the prosthetic replacement of the shoulder. The state of the glenoid cannot be adequately assessed from radiographs alone (Fig. 5), but CT is useful. This can show the extent and location of unsupported bone, and allow planning of the placement of the keel or peg of the glenoid component into good trabecular bone. Knowledge of the version of the glenoid ensures that the keel is directed appropriately. In an anteverted glenoid there is a risk of the keel penetrating the posterior surface of the scapula; in a retroverted glenoid the anterior surface may be breached.

Altered vertical inclination of the glenoid, particularly the superior inclination in rheumatoid arthritis could lead to upward-facing placement of the glenoid component. This would alter the mechanics of the shoulder, make the humeral component more likely to migrate 
superiorly, and possibly lead to rotator-cuff impingement. Undetected erosion of the glenoid could lead to medial placement of the glenoid, particularly in osteoarthritic shoulders, and this may produce inaccurate softtissue tension.

A knowledge of the pattern of glenoid erosion from CT scans enables the choice to be made of the most appropriate design of glenoid component, and will show

\section{REFERENCES}

Barrett WP, Franklin JL, Jackins SE, Wyss CR, Matsen FA III. Total shoulder arthroplasty. J Bone Joint Surg [Am] 1987; 69-A:865-72.

Cofield RH. Total shoulder arthroplasty with the Neer prosthesis. $J$ Bone Joint Surg [Am] 1984; 66-A:899-906.

Crossan JF, Vallance R. Clinical and radiological features of the shoulder joint in rheumatoid arthritis. J Bone Joint Surg [Br] 1980; 62-B:116.

Cyprien JM, Vasey HM, Burdet A, et al. Humeral retrotorsion and glenohumeral relationship in the normal shoulder and in recurrent anterior dislocation (scapulometry). Clin Orthop 1983; 175:8-17.

Deutsch AL, Resnick D, Mink JH. Computed tomography of the glenohumeral and sternoclavicular joints. Orthop Clin North Am 1985; 16:497-511.

Friedman RJ, Hawthorne KB, Genez BM. The use of computerized tomography in the measurement of glenoid version. J Bone Joint Surg [Am] 1992; 74-A:1032-7.

Iannotti JP, Gabriel JP, Schneck SL, Evans BG, Misra S. The normal glenohumeral relationships: an anatomical study of one hundred and forty shoulders. J Bone Joint Surg [Am] 1992; 74-A:491-500. whether bone grafting is required to achieve the correct version and inclination. It also allows surgery to be planned to obtain the most secure fixation in the available bone. Careful preoperative assessment of the state of the glenoid is essential and this can be provided by $\mathrm{CT}$.

No benefits in any form have been received or will be received from a commercial party related directly or indirectly to the subject of this article.

Kelly IG, Foster RS, Fisher WD. Neer total shoulder replacement in rheumatoid arthritis. J Bone Joint Surg [Br] 1987; 69-B:723-6.

Lettin AWF, Copeland SA, Scales JT. The Stanmore total shoulder replacement. J Bone Joint Surg /Br] 1982; 64-B:47-51.

McCoy SR, Warren RF, Bade HA, Ranawat CS, Inglis AE. Total shoulder arthroplasty in rheumatoid arthritis. J Arthroplasty 1989; 4:105-13.

Neer CS II. Reconstructive surgery and rehabilitation of the shoulder. In: Kelly WN, Harris ED, Ruddy S, Sledge CB, eds. Textbook of rheumatology. Philadelphia, etc: WB Saunders Co, 1985:1944-59.

Neer CS II, Morrison DS. Glenoid bone-grafting in total shoulder arthroplasty. J Bone Joint Surg [Am] 1988; 70-A:1154-62.

Neer CS II, Watson KC, Stanton FJ. Recent experience in total shoulder replacement. J Bone Joint Surg [Am] 1982; 64-A:319-37.

Randelli M, Gambrioli PL. Glenohumeral osteometry by computed tomography in normal and unstable shoulders. Clin Orthop 1986; 208:151-6.

Sillar P, Meszaros T, Horvath F, Keri L, Lengyel E. Gerontological aspects of degenerative changes of the shoulder-joint (radiological and clinical studies). ZFA 1979; 34:411-21. 